\title{
ESTUDO EXPLORATÓRIO DA COMPETÊNCIA TRADUTÓRIA DE TRADUTORES OUVINTES INTERMODAIS EM RELAÇÃO À SUA PRÁTICA
}

\author{
Eduardo Andrade Gomes ${ }^{1}$ \\ ${ }_{1}^{1}$ Universidade Federal de Minas Gerais, Belo Horizonte, Minas Gerais, Brasil
}

Thaís Fleury Avelar²

²Universidade Federal de Goiás, Goiânia, Goiás, Brasil

Resumo: A competência tradutória (intermodal) é a reunião de atitudes, habilidades e saberes especializados imprescindíveis ao tradutor para a transposição de informações entre línguas, distintas ou não. Segundo o grupo PACTE, tal competência é constituída por componentes que poderão ser tensionados a partir de aspectos como a direcionalidade do processo tradutório, o tipo e o gênero textual, e as modalidades (de uso) das línguas envolvidas. Sendo assim, empreendemos uma pesquisa de ordem exploratória na qual oito tradutores ouvintes, da região Sudeste e Sul do país, responderam a uma entrevista semiestruturada na qual abordava questões referentes à sua prática tradutória. Os dados demonstram que, apesar desses tradutores preferirem atuar na direção do português escrito para a Libras oral, a manifestação corporal, gestual e visual e o uso do espaço são considerados desafiadores, principalmente por envolver o registro desse produto em vídeo. Além disso, independentemente dos textos a serem traduzidos, as consultas em fontes documentais, lexicais e terminológicas são ações essenciais no trabalho desses profissionais. Diante disso, ressaltamos a importância em tratar a competência tradutória intermodal, defendida por Rodrigues (308), de maneira a oferecer aos tradutores formações que englobem atividades nas duas direções, emprego de ferramentas de busca e maior variedade de textos.

Palavras-chave: Competência tradutória; Intermodalidade linguística; Língua de Sinais; Tradutores ouvintes; Português-Libras 


\title{
EXPLORATORY STUDY OF THE TRANSLATION COMPETENCE OF INTERMODAL HEARING TRANSLATORS IN RELATION TO ITS PRACTICE
}

\begin{abstract}
The translatory (intermodal) competence is the gathering of attitudes, skills and specialized knowledge essential to the translator for the transposition of information between languages, distinct or not. According to the PACTE group, this competence consists of components that can be tensioned from aspects such as directionality of the translation process, type and textual genre, and the (use) modalities of the languages involved. Thus, we undertake an exploratory research in which eight hearing translators, from the Southeast and South regions of the country, responded to a semi-structured interview in which it addressed questions regarding their translation practice. The data demonstrates that, despite these translators to act in the direction of portuguese written to the oral Libras, the body manifestation, gestural and visual and the use of space are considered challenging, mainly by involving the recording of this video product. In addition, regardless of the texts to be translated, consultations in documentary, lexical and terminological sources are essential actions in the work of these professionals. In view of this, we emphasize the importance in treating intermodal translation competence, advocated by Rodrigues (308), in order to offer the translators formations that encompass activities in both directions, use of search tools and greater variety of texts.
\end{abstract}

Keywords: Translatory competence; Linguistic intermodality; Sign language; Hearing translators; Portuguese-Libras

\section{Introdução}

Os Estudos da Tradução e da Interpretação envolvendo as línguas de sinais têm se ampliado e consolidado enquanto área, uma vez que as publicações, sobretudo a nível de pós-graduação (e.g., mestrado e doutorado), vêm caminhando em uma direção que evidencia a articulação e a delineação entre os aparatos teóricos e metodológicos de pesquisa como apontam Santos $(289,377)$ e Rodrigues e Beer (33-34). Entretanto, os trabalhos que abordam e que 
discutem especificamente a tradução ${ }^{1}$ interlinguística ${ }^{2}$ e intermodal (i.e., entre uma língua vocal-auditiva e uma língua gestual-visual), estão em relativo crescimento.

Para ilustrar esse cenário, podemos citar algumas publicações como Quadros e Souza (177), que debatem aspectos da tradução do português escrito para a Língua Brasileira de Sinais (Libras) oral ${ }^{3}$ enquanto encenação; Souza (20), apresentando uma explanação da tradução de textos em português escrito para Libras oral do curso de Letras-Libras da Universidade Federal de Santa Catarina como performance; Klamt (107), que elucida as estratégias empregadas na tradução de uma poesia em Libras oral, de autoria surda, para o português escrito; Rigo (458), implementando uma análise textual acerca do processo tradutório da Libras oral para o português escrito de uma tese de doutoramento; Segala e Quadros (354), discutindo, a partir de materiais traduzidos do mesmo curso e universidade supracitada por Souza (20), a aplicabilidade e a concepção da tradução intermodal do português escrito para a Libras oral; Rigo (173), na qual declara, sob o ângulo dos elementos do design editorial, as soluções tradutórias utilizadas na tradução de um material acadêmico em português escrito para a Libras oral; Santos (95), refletindo quanto à adoção de um polissistema literário e cultural na tradução de textos sensíveis do português escrito para a Libras oral; Sutton-Spence (194), que aborda uma tradução comentada do português escrito para a Libras oral do clássico Grande Sertão Veredas de João Guimarães Rosa; Dias e Nascimento (60), retratando a tradução comentada do português escrito para a Libras oral de

\footnotetext{
${ }^{1}$ Embora as diversas ponderações feitas neste trabalho se apliquem tanto à tradução e ao tradutor quanto à interpretação e ao intérprete, o nosso cerne será a tradução. ${ }^{2}$ De agora em diante, ao longo de todo o texto, os termos "intermodal", "intramodal gestual-visual", "intramodal vocal-auditiva" e suas eventuais variâncias, "inter/intramodalidade", serão concebidos como modalidade da língua, conforme alvitra Rodrigues (305). Por isso, a fim de evitar a redundância, não será mais utilizado o termo "interlinguística".

${ }^{3}$ Este termo faz menção à oralidade, maneira interpessoal sinalizada, face a face, em que, neste caso, a língua gestual-visual é articulada e produzida.
}

Cad. Trad., Florianópolis, v. 41, nº esp. 2, p. 40-67, ago/dez, 2021. 
um protocolo avaliativo denominado Escala de Ansiedade à Matemática a pessoas surdas; Fonseca, Gonçalves e Zampier (43-44) que, por meio de um estudo experimental, averiguam o impacto da competência tradutória quanto ao esforço cognitivo, à percepção de tradução e à subjetiva satisfação em uma atividade de tradução da Libras oral para o português escrito por tradutores experientes e bilíngues não tradutores; Andrade (17), examinando as estratégias de antropomorfismo aplicadas por distintos tradutores surdos na tradução do português escrito para a Libras oral de três versões em vídeo da mesma fábula, "Os três porquinhos"; Avelar (17-18), que verifica o processo tradutório de um texto acadêmico do português escrito para a Libras oral, realizado por tradutores ouvintes e tradutores surdos, durante a atuação em dupla; e Carneiro, Vital e Souza (135), descrevendo o processo metodológico de produção de textos traduzidos do português escrito para a Libras oral, cotejando-o com o procedimento adotado na produção de textos escritos entre línguas vocais-auditivas.

As treze publicações sobreditas não expõem os trabalhos e as pesquisas de tradução intermodal desenvolvidas em sua totalidade no país, porém evidenciam que as atividades tradutórias na direção da Libras para o português estão, aparentemente, em menor escala, assumindo consonância ao apontamento feito por Rigo (462). Por outro lado, notamos que a promoção e a execução dessas tarefas (i.e., tradutórias) têm-se amplificado e se fortalecido, principalmente no ambiente acadêmico, como destaca Rodrigues (307).

Tradicionalmente, mesmo havendo a identificação nas obras, os tradutores são profissionais que passam despercebidos aos olhos e às mãos dos leitores, ou seja, de quem acessa o material na língua de chegada, sendo figurados como agentes secundários, conforme ponderam Santos e Romanelli (269). Contudo, tratando-se de línguas de sinais, essa realidade é totalmente diferente, visto que, caso a tradução intramodal (i.e., entre línguas de mesma modalidade) gestual-visual ou intermodal seja para essa língua em vídeo, o tradutor estará, obrigatoriamente, exposto física e visualmente ao produzir as informações por meio dos movimentos em todo o seu corpo 
- cabeça, membros, tronco - , das expressões manuais e não-manuais e da utilização morfossintática do espaço (Souza 122). A essa conjuntura de atuação, devidamente imposta pela condição modal (i.e., gestual-visual) dessas línguas, Rodrigues (307) a denomina de "performance corporal-visual", devido à necessidade de organização espacial e à incorporação linguística e gestual de informações.

Autores como Souza (121) e Spooner et al. (115) a intitulam de "performance de ator", por admitirem, além dos quesitos supracitados, conhecimentos e habilidades adicionais, a saber, o posicionamento em frente às câmeras e a construção da sinalização (i.e., expressão usada para referenciar a produção de fala em língua de sinais) como um todo nesse enquadramento. Por isso, Souza (174) ratifica "a impossibilidade de separar o texto de sua expressão corporal em sinais [...]". Carneiro, Vital e Souza (141), por sua vez, apesar de compreenderem que essa manifestação corporal é indispensável, são mais comedidos ao optar pelo termo "tradutor -apresentador", considerando que o profissional estará externando o texto de chegada por meio do vídeo. Vale ressaltar que o registro da produção em sinais em meios digitais (e.g., vídeos) é algo mais comum e tem crescido com o advento da tecnologia, configurandose como tradução intramodal gestual-visual/intermodal não-escrita, como orienta Rodrigues (309). É possível realizar a tradução intramodal gestual-visual/intermodal escrita, mas, pelo menos no Brasil, os sistemas de escrita de sinais, apesar de existentes, ainda não são amplamente usados, ensinados e disseminados socialmente. Alguns desses sistemas de escrita de sinais são o SignWriting (Sutton 1996 apud Stumpf 53), a Escrita das Línguas de Sinais (ELiS) (Barros 25), o Sistema de Escrita da Libras (SEL) (Lessade-Oliveira 165) e a Escrita Visogramada das Línguas de Sinais (VisoGrafia) (Benassi 20).

Diante da especificidade posta ao processo tradutório para uma língua gestual-visual e da demanda, cada vez maior, por materiais, em Libras, como artigos, avaliações, documentos, editais, obras literárias, entre outros, enquanto direito linguístico e cultural da comunidade surda, como pontuam Nascimento e Nogueira (106), 
é necessário que reflitamos quanto à competência tradutória que os tradutores precisam adquirir para o desenvolvimento de um bom trabalho. Sendo assim, buscamos, neste artigo, tratar dessa competência, sob a percepção de profissionais tradutores ouvintes intermodais, que apresentam a Libras como segunda língua e o português como língua materna e, assim, desenvolvem algumas atividades de tradução. Posto isso, a tradução intermodal será problematizada principalmente na direção do português escrito para a Libras oral.

A seguir, apresentaremos uma sucinta discussão a respeito da competência tradutória e a sua implicação com a intermodalidade, a partir das considerações tecidas por um grupo de oito tradutores ouvintes profissionais que atuam no par linguístico português-Libras em uma entrevista semiestruturada.

\section{Pressupostos teóricos: competência tradutória (intermodal)}

A tradução é uma atividade de natureza complexa centrada na transferência de material textual, de significados e sentidos, entre línguas distintas e/ou mesma língua que, apesar de ser um hiperônimo, apresenta suas características e particularidades. Para além da ordem tecnicista, Loguercio e Silva (70) a concebem como "um conhecimento cuja especificidade passa pela mediação entre culturas, o que, apesar de apontar para um entre-lugar, nunca ocorre de forma neutra, mas antes é marcada por tomadas de decisão e posicionamentos".

Rodrigues (303) menciona que o processo de tradução requer o texto disponibilizado em um suporte físico ou virtual (e.g., papel, vídeo). Nesse caso, o tradutor acessará irrestritamente todo o conteúdo de partida, bem como terá a possibilidade de recorrer aos apoios externos como dicionários, glossários, obras adicionais e paralelas, colegas de profissão e/ou das áreas de especialidade que a temática a ser traduzida se inserir, entre outros. Segundo Rodrigues (302), em relação ao tempo e ao ritmo de trabalho, o tradutor 
poderá organizá-lo e dimensioná-lo, na maioria das situações, da forma que melhor lhe convir, respeitando o prazo acordado para o serviço, não ficando refém, necessariamente, do tempo imposto pelo orador e/ou pelo texto de partida durante a sua produção, como acontece na interpretação. Isso implica, também, em uma segmentação espacial e temporal entre o autor, o tradutor e o interlocutor, diferentemente da interpretação, em que, geralmente, todos esses agentes estão reunidos. Ainda, terá a oportunidade de revisar e de editar todo o produto emitido antes da entrega final, previamente à sua disponibilização, não demonstrando ao público de chegada quais foram as dificuldades e os problemas de tradução que participaram do processo.

Frente a essas e demais peculiaridades imbricadas ao processo de tradução em si, é notório que os tradutores precisam possuir um conjunto de conhecimentos, técnicas e habilidades que os capacite e os conduza ao adequado desempenho dessas tarefas, compondo a sua competência tradutória, como salientam Hurtado Albir (19), Gonçalves (117) e Rodrigues (290).

Para, então, alcançar essa competência tradutória, determinados grupos e pesquisadores têm se debruçado a pensar quais seriam os componentes dessa competência, ou melhor, em subcompetências, bem como em modelagens para tal. Rodrigues (291) nos revela alguns desses modelos alvitrados especialmente no âmbito europeu. Entretanto, neste trabalho, optamos por acompanhar o modelo atualizado proposto pelo grupo $\mathrm{PACTE}^{4}$, que se fundamenta numa perspectiva holística de natureza cognitivo-construtivista.

Hurtado Albir (397) apresenta os seis componentes, que constituem a competência tradutória, do atual modelo do grupo de pesquisa. Temos, portanto, a subcompetência bilíngue que alude aos conhecimentos lexicais, gramaticais, pragmáticos, sociolinguísti-

\footnotetext{
${ }^{4}$ Este grupo de pesquisa, denominado Proceso de Adquisición de la Competencia Traductora y Evaluación/Processo de Aquisição da Competência Tradutória (PACTE), está estabelecido na Universitat Autònoma de Barcelona e é liderado pela pesquisadora e professora Dra. Amparo Hurtado Albir. https://grupsderecerca. uab.cat/pacte/en.
}

Cad. Trad., Florianópolis, v. 41, no esp. 2, p. 40-67, ago/dez, 2021. 
cos e textuais das línguas envolvidas, os quais são imprescindíveis para o estabelecimento da comunicação em duas línguas, para o seu domínio e uso. A subcompetência extralinguística que agrega os conhecimentos declarativos ${ }^{5}$ referentes às culturas das línguas em questão, entre outros conhecimentos de mundo e de domínios específicos. A subcompetência de conhecimentos sobre tradução composta pelos saberes teóricos e pelos aspectos que regem o âmbito profissional, assim como de conhecimentos sobre o processo tradutório e seus elementos. A subcompetência instrumental que se refere ao trato com as ferramentas, os materiais tecnológicos e as fontes de documentação operadas em favor da tradução. A subcompetência estratégica que visa os conhecimentos operacionais para subsidiar todo o processo tradutório, integrando as demais subcompetências e permitindo que as deficiências sejam compensadas. Por fim, o componente denominado psicofisiológico, que abriga as questões cognitivas acerca da memória, da percepção, da atenção e dos aspectos atitudinais como as emoções e a autonomia. Dessas subcompetências, conforme Hurtado Albir (396), destaca-se que a de conhecimentos sobre tradução, a instrumental e a estratégica são desenvolvidas estritamente pelos profissionais tradutores, enquanto a bilíngue e a extralinguística podem ser compartilhadas com pessoas que dominam duas línguas, como no caso da Libras e do português.

É relevante ressaltar, de acordo com Rodrigues (297), que tais componentes e/ou saberes especializados, apesar de interligados, apresentam hierarquia em sua disposição. Assim, a subcompetência estratégica posiciona-se em um local central, regendo, portanto, as demais. Entretanto, Rodrigues (303) indica que o diálogo entre as subcompetências poderá se alterar, implicando em maior ou menor intensidade, a depender de alguns critérios como a direcionalidade ${ }^{6}$

\footnotetext{
${ }^{5}$ Estes conhecimentos, na tradução, pela concepção do PACTE, são respaldados no "saber o quê", sendo explanado verbalmente e adquirido a partir de informações e uso controlado e responsável.

${ }^{6}$ Nesta ocasião, priorizamos o uso de "direcionalidade", sem especificar quais as direções, uma vez que os tradutores, em contexto de trabalho, podem ser surdos
}

Cad. Trad., Florianópolis, v. 41, $\mathrm{n}^{0}$ esp. 2, p. 40-67, ago/dez, 2021. 
da tradução, os pares linguísticos, a temática e o gênero textual do material a ser traduzido, a experiência do profissional, o contexto situacional, a modalidade de uso das línguas, entre outros.

Em relação à direcionalidade e aos pares linguísticos, um fator intrínseco e substancial que perpassa os processos tradutórios construídos entre línguas vocais-auditivas e gestuais- visuais é a diferença de modalidade da língua (i.e., sistemas físicos ou biológicos de percepção e de produção linguística) (Rodrigues 43). Por isso, o mesmo autor, em recente publicação, nos incita a refletir quanto à existência/necessidade de uma possível competência tradutória intermodal, isto é,

ao desenvolvimento de conhecimentos e habilidades necessários tanto à exploração corporal dos dispositivos linguísticos específicos das línguas de sinais, durante a sinalização [...], quanto à capacidade visual-cognitiva de ler a totalidade das informações gestuais e espaciais, as quais estão expressas quadridimensionalmente por meio da integração desses dispositivos linguísticos específicos, durante a vocalização [...], ambas vinculadas à habilidade de se administrar a possibilidade de sobreposição das línguas de maneira vantajosa. (Rodrigues 310).

Entoado ao atual modelo do grupo PACTE, para compor essa competência tradutória intermodal, além das subcompetências bilíngue, extralinguística, de conhecimentos sobre tradução, instrumental, estratégica e componentes psicofisiológicos, Rodrigues (311312, grifos do autor) preconiza o acréscimo de elementos referentes às "habilidades corporais motoras de codificação integrada de propriedades gestuais e espaciais e, também, às habilidades visuais de interpretação do conjunto de informações gestual e espacialmente codificadas". Essas seriam para contemplar a tradução nas duas direções. Partindo, por exemplo, do texto escrito em português para

e/ou ouvintes filhos de pais surdos ou não.

Cad. Trad., Florianópolis, v. 41, no esp. 2, p. 40-67, ago/dez, 2021. 
a Libras oral, o processo de sinalização roga ao profissional uma compreensão e uma exploração corporal e espacial, de modo que consiga manejar, satisfatoriamente, os itens linguísticos dessa língua. Em outra direção, da Libras oral para o português escrito, o tradutor requer aspectos visuais-cognitivos para assimilar todas as mensagens postas gestual e visualmente no espaço.

Desta feita, uma factível subcompetência oriunda dos saberes especializados supracitados poderia estar intimamente atrelada à subcompetência bilíngue e extralinguística, que se ocupam, diretamente, das línguas enredadas no processo tradutório. Essas, por sua vez, assim como as demais, seriam dirigidas pela subcompetência estratégica, e os componentes psicofisiológicos transcenderiam a todo o modelo como já defendido pelo grupo PACTE. Assim, em suma, para Araújo e Fonseca (80), a tradução é "resultado da interação entre as subcompetências do tradutor, assim como de seus processos cognitivos e fisiológicos durante o ato tradutório".

\section{Metodologia: procedimentos e dados}

Neste artigo, optamos pela pesquisa exploratória por entendê-la, segundo Gil (27), como um método qualitativo que busca, de forma geral, compreender, descrever e explicar o objeto em estudo, para que sejam produzidas novas informações, sem exteriorizar, obrigatoriamente, dados numéricos e estatísticos. Duarte (215) acrescenta que essa investigação proporciona ao pesquisador explorar e ampliar os aparatos teóricos, a partir dos dados encontrados em harmonia com os objetivos do trabalho.

Ainda que a entrevista não seja o único mecanismo de coleta de dados da abordagem qualitativa, concebemos que essa poderá nos atender neste estudo, uma vez que pretendemos conhecer o perfil e as impressões de tradutores ouvintes intermodais profissionais a respeito do seu trabalho e de que forma essas especificidades corroborariam, a priori, à compreensão da competência tradutória entre línguas de modalidades vocais-auditivas e gestuais-visuais. 
Sendo assim, contatamos quinze tradutores ouvintes da região Sudeste e Sul do país que atuam em instituições de ensino superior, porém, apenas oito, três mulheres e cinco homens, tiveram disponibilidade para participar desta pesquisa. A escolha por esse grupo de pessoas ouvintes é pelo fato de que, para todos, a Libras e o português se enquadrariam como segunda ${ }^{7}$ e primeira língua, respectivamente. $\mathrm{O}$ contato foi feito por redes sociais e aplicativos de mensagens explicando o objetivo da nossa pesquisa e que se pautaria em duas etapas. A primeira seria o preenchimento escrito em português de um quadro informativo quanto ao perfil dos profissionais e a segunda seria uma entrevista individual semiestruturada realizada por vídeo no referido aplicativo de mensagens ou Skype ${ }^{8}$. Essa, por sua vez, seria efetuada em português oral e gravada para posterior análise. Em média, as entrevistas tiveram a duração de doze minutos.

Os critérios pautados para construir o perfil dos participantes foram (i) a idade atual; (ii) a formação acadêmica/escolaridade, (iii) o período, em idade, de aquisição ou aprendizagem da Libras; (iv) a atuação como tradutor e/ou intérprete de português-Libras mensurada em anos e; em mesma escala temporal (e.g., anos), (v) a experiência profissional especificamente com tradução intermodal ou intramodal gestual-visual escrita e não-escrita. É importante salientar que todos os tradutores assinaram o Termo de Consentimento Livre e Esclarecido (TCLE), concordando em participar deste estudo. Por conseguinte, para manter as suas identidades preservadas, os nomeamos com a letra $\mathrm{T}$ (i.e., tradutor), com a letra F ou M (i.e., gênero biológico) e um número.

A seguir, é apresentado o roteiro predefinido para a entrevista individual semiestruturada.

\footnotetext{
${ }^{7}$ Algumas pessoas ouvintes podem ser falantes nativos da Libras, possuindo-a como primeira língua, em virtude de serem filhos de pai e/ou mãe surdos sinalizantes. Contudo, nenhum dos tradutores participantes se encaixam nessa categoria.

${ }^{8}$ É um software que viabiliza a comunicação e a interação por meio de mensagens escritas, em áudio e em vídeo. Para a sua utilização é necessário que o dispositivo no qual o aplicativo ou o site se encontra esteja conectado à internet.
}

Cad. Trad., Florianópolis, v. 41, no esp. 2, p. 40-67, ago/dez, 2021. 
Quadro 01 - Roteiro básico para a entrevista semiestruturada

1 - Você tem mais dificuldades em traduzir da Libras oral em vídeo para o português escrito ou do português escrito para a Libras oral em vídeo? Por quê?

2 - O que você considera como mais difícil na tradução do português escrito para a Libras oral? E da Libras oral para o português escrito?

3 - Quais são as(os) habilidades/ estratégias/ conhecimentos indispensáveis ao tradutor que traduz do português escrito para a Libras oral em vídeo?

4 - Você acredita que os tipos de textos interferem na sua atuação?

Quais são os textos que você não se sente preparado para traduzir?

Fonte: Os autores, inspirados em Avelar (138-139).

Este molde de entrevista, conforme aponta Manzini (13), se configura como um roteiro básico, consoante ao objetivo proposto, podendo ser complementado e/ou substituído, a depender das respostas emitidas pelo entrevistado, e empregado para orientar e organizar o pesquisador no momento em que estiver interagindo com o informante. Optamos por tal modelo, em detrimento a um questionário rígido, por considerar que a interação face a face, mesmo que virtualmente, nos permitiria acessar os pontos importantes e complementares às respostas dadas preliminarmente aos questionamentos feitos. Logo, esse tipo de entrevista pode potencializar a obtenção de dados alinhados aos nossos objetivos.

Subsequentemente, para fins de análise, transcrevemos, todas as passagens, utilizando o software gratuito EUDICO Language Annotator (ELAN), elaborado pelo Max Planck Institute of Psycholinguistics da Holanda, na qual relaciona o conteúdo a ser analisado, com a sua respectiva transcrição, acompanhando o tempo de cada termo e criando as trilhas específicas, submetendo-se aos anseios e aos objetivos do(s) pesquisador(es) (Quadros e Pizzio 17; 
Mccleary, Viotti e Leite 276). Como nosso intuito é conhecer as percepções discursivas dos tradutores ouvintes profissionais no que tange a atuação nesse âmbito e a sua relação com a competência tradutória intermodal, não enveredamos por uma análise linguística descritiva. Para cada pergunta da entrevista havia uma trilha transcrita, totalizando oito.

\section{Resultados}

O grupo amostral de tradutores ouvintes intermodais profissionais nos revela, de modo geral, uma aparente homogeneidade, não por sua padronização, mas em um viés quanto à formação. Todos possuem uma graduação, sendo quatro desses cursos superiores alinhados à grande área do conhecimento das Ciências Humanas, três à Linguística, Letras e Artes, na qual um deles é a formação específica em Bacharelado em Letras com habilitação em Língua Brasileira de Sinais, e um às Ciências Exatas. Vale frisar que essas áreas são definidas conforme parâmetros elencados pela Coordenação de Aperfeiçoamento de Pessoal de Nível Superior (CAPES).

Os informantes TF2 e TM4 possuem pós-graduação stricto sen$s u$ (e.g., mestrado) em Educação e Letras, respectivamente, e TF1, TF3, TM5 e TM7 apresentam pós-graduação lato sensu em cursos da área de Educação/Docência e de Tradução e Interpretação de português-Libras. Os tradutores aprenderam a Libras, como segunda língua, em média aritmética, aos 16 (dezesseis) anos de idade, e possuem experiência profissional com tradução e/ou interpretação há cerca de 6,1 (seis vírgula um) anos. Essas informações, apesar de particulares, nos auxiliam a balizar os dados, para que não haja grandes discrepâncias entre os profissionais participantes.

Embora Rodrigues (311) discorra que a possível competência tradutória intermodal deva ser melhor apurada por meio de estudos experimentais, concebemos que as respostas provenientes das entrevistas aqui pleiteadas podem, também, ratificar essa questão, devido à experiência de cada um dos tradutores ouvintes. 
Inicialmente, quando questionados a respeito das direções da tradução, todos indicaram a preferência do português escrito para a Libras oral. A justificativa para tal se baseia na maior frequência de trabalhos dessa natureza, por conta das políticas de inclusão e difusão de materiais traduzidos, e admitirem à maior facilidade e ao conforto em compreender o texto de partida, como ressalta o tradutor ouvinte 5 (TM5):

"O português possui um leque enorme e muitas ferramentas de pesquisa para se entender o texto-fonte [texto de partida] e o mais difícil no processo de tradução é o entendimento. O sentido inverso se complica quando um surdo apresenta um sinal que não tenho como pesquisar."

A resposta de TM5, bem como a de TM4: "acho mais dificil relacionar as palavras aos sinais" e a de TF3: "a Libras tem uma variação linguística muito grande e isso é um fator que pode dificultar a tradução para o português" remonta uma lacuna na formação inicial e/ou continuada, acadêmica e/ou empírica dos profissionais. Essa pode ocorrer, por exemplo, por não se problematizar e desenvolver atividades específicas que insira a primeira língua (e.g., português) como texto de chegada e pela maneira como o ensino e/ou a prática linguística de segunda língua (e.g., Libras) tem sido discutido (Rodrigues 204). Assim, evidencia-se que a subcompetência bilíngue não está, de fato, sendo trabalhada e aperfeiçoada em ambas as línguas de trabalho. Corroborando as afirmações supracitadas, a nível superior, apenas uma informante deste estudo, TF1, possui formação específica na área, e destaca que "[...] não tive quase nenhuma prática com tradução no Letras -Libras. Algumas práticas que tive foi no trabalho".

Além da provável insuficiência de atividades e de discussões formativas quanto à direcionalidade, a própria natureza da tradução parece não ser tão difundida e indagada nesses cursos, em detrimento da interpretação. Mesmo que, de fato, grande parte das 
tarefas do cotidiano estejam mais próximas ou direcionadas à interpretação, a tradução intermodal também é factível de ser realizada e, cada vez mais, tem conquistado espaço, sendo as avaliações do Exame Nacional do Ensino Médio (ENEM) traduzidas do português escrito para a Libras oral em vídeo um dos principais exemplos. Tal constatação nos evoca uma urgente reflexão para a reformulação dos desenhos curriculares desses cursos de formação.

Para tentar contornar o cenário posto como dificuldade pelos tradutores intermodais, cabe-lhes utilizar as ferramentas tecnológicas e o contato com colegas surdos e ouvintes para melhor compreender o contexto situacional da exposição corporal e imagética e, assim, relacionar as terminologias em sinais às palavras, aos contextos e aos sentidos da língua vocal-auditiva. Essa seria a subcompetência instrumental, imprescindível ao tradutor e viabilizada pela aparente flexibilidade em relação ao tempo e ao ritmo de trabalho, bem como ao acesso integral ao texto de partida.

A esse respeito, TM8 argumenta que " a tradução para o português escrito demora mais, pois precisa retornar várias vezes à mesma parte do vídeo até captar toda a ideia". Essa recuperação de enunciados do texto de partida é natural a qualquer processo tradutório para que as informações sejam concatenadas e estabeleçam uma lógica significativa. Pelo fato do material estar disponível irrestritamente ao tradutor, é possível que haja reorganizações estruturais e sequenciais no texto de chegada ao adiantar ou postergar alguma informação, de maneira que o produto seja mais compreensível ao público. Todavia, a especificidade gestual-visual das línguas de sinais em vídeo acarreta, realmente, em sucessiva manipulação para pausas, já que seria impraticável sistematizar e registrar as mensagens de forma simultânea, como ocorre em um dos modos de interpretação.

Consequentemente, um maior esforço cognitivo se instala nessa etapa (i.e., apreensão do texto de partida), como sugerem Fonseca, Gonçalves e Zampier (41) ao efetuarem um estudo experimental, pressupondo maior atenção visual dos profissionais durante a atividade tradutória, já que, de acordo com os autores, ocorrerá a 
"coordenação de informações de diversos canais [corporais, gestuais e visuais]". Proporcionalmente associado ao esforço, está o tempo gasto na fase de compreensão do material textual. Kiraly (120), Pavlović e Jensen (107) e Ferreira (55) anunciam que, em tradutores intramodais vocais-auditivos, o tempo despendido e o esforço cognitivo às tarefas de expressão em segunda língua são maiores, contribuindo para a destreza e a preferência pela direção em que a produção ocorre na língua materna diferenciando-se, novamente, dos tradutores intermodais. Isso pode estar atrelado ao fato de tais textos serem materializados, em sua maioria, na modalidade de uso escrita, e estarem dispostos de uma só vez. Vale frisar que a questão temporal pode estar relacionada, também, às dificuldades que o tradutor tende a se deparar com o texto de partida e/ou de chegada. Assim, para Ferreira (39), "quanto maior a dificuldade de um texto, mais tempo de dedicação é exigido". Ainda, após toda a tradução realizada, independentemente de qual seja a direção e o par linguístico, é possível e recomendável que o profissional reveja ambos os textos, e faça as devidas correções e edições.

Em relação à tradução para o registro da Libras oral em vídeo, todos citaram como indispensável o conhecimento das duas línguas envoltas no processo tradutório, o alcance prévio ao material a ser traduzido e a familiaridade com a câmera. Mesmo assim, a maior dificuldade retratada se refere à exposição corporal e imagética e aos aspectos linguísticos da Libras. TF2 é categórica ao dizer que:

"a câmera impõe medo, pois ficará salvo um texto que nós traduzimos e que depois poderá ser visto por todos. Se fizermos algo ruim, as pessoas vão julgar. Às vezes é dificil também marcar os referentes no espaço quando são muitos, como acontece em narrativas e histórias, e dosar a intensidade das expressões."

Esse excerto exprime o que Souza (123) e Rodrigues (310) defendem em seus trabalhos. Segundo os autores, o tradutor intermodal, 
ao traduzir do português escrito para a Libras em sua versão oral, necessitará apresentar-se fisicamente por meio de um processo de encenação/performance corporal-visual, sendo que, para Ferreira e Silva-Neto (84) a visibilidade "do tradu(a)tor o situa num processo de atuação". Isso desemboca no controle em relação a aplicação dos dispositivos (não) linguísticos como as expressões não-manuais, o uso do espaço, o movimento do corpo, entre outros.

Além desses aspectos linguísticos, se seguirmos uma perspectiva mais funcionalista da tradução, podemos entender que o tradutor é o produtor do texto em Libras para a comunidade surda, já que se "apropria da intenção do emissor ou do iniciador para produzir um instrumento comunicativo para a cultura alvo, ou um documento para a cultura alvo a partir de uma comunicação da cultura fonte" (Nord 33). Esse ponto afina-se à subcompetência extralinguística necessária ao profissional.

Não obstante, o trecho acima de TF2 expõe a fragilidade que a tradutora ouvinte intermodal sente em relação ao processo tradutório como um todo e, principalmente, o olhar crítico do público ao receber o material traduzido. Esse aspecto conecta-se, além do caráter perene da tradução em estar documentada, à durabilidade textual, na qual espera-se qualidade coerente, coesiva e discursiva do texto de chegada, estando adequado ao texto de partida, como observa Alves (121). Por isso, em formação, é importante conceber os componentes psicofisiológicos como parte integrante da atividade, devido à forte influência que esses podem exercer no profissional e impactar o seu trabalho.

Tratando-se de vídeos, do ponto de vista técnico, é interessante que, em perspectiva multimodal e verbo-visual, o tradutor conheça os procedimentos, os objetos, as imagens, as cores, os sons e os layouts que serão utilizados para compor o material em si. Assim, todos esses elementos expressivos e visuais poderão dialogar e interagir com o discurso verbal e visual da Libras, engendrando um significado unificado ao público receptor deste produto (Nascimento 131). Para além da perspectiva tradutória em vídeos, é importante desenvolver, nos tradutores, habilidades concernentes ao 
procedimento técnico e tecnológico de organização, manipulação e edição de câmeras, de iluminação, de programas e de softwares que integram todo o processo. Essas seriam, portanto, as subcompetências instrumentais.

Outras variáveis também podem influenciar o processo tradutório como os tipos e os gêneros de textos a serem traduzidos, já que, em síntese, são, respectivamente, estabelecidos por sua estruturação e sua forma, e se aplicam com finalidades sociais e comunicativas delineadas.

Ratificando essa questão, os tradutores foram unânimes ao citá -la como um fator importante a ser considerado. Para TM7, "traduzir um tipo de texto que temos mais aptidão facilita o trabalho, porque sabemos como é a estrutura". Conhecer ou mesmo presumir a organização de determinado material textual é um fato que auxilia o tradutor no seu estudo e preparação para desempenhar a sua atividade. No entanto, não é suficiente.

Desta feita, os participantes foram indagados a respeito de qual(is) texto(s) não se sentiriam preparados para traduzir. Como essa pergunta era ampla, alguns participantes indicaram mais de um tipo de texto, totalizando onze respostas. Três deles apontaram os textos religiosos, quatro respondentes os textos do âmbito jurídico, dois citaram textos do contexto político e dois mencionaram os textos acadêmicos ligados à área biológica e da saúde. Em todos, a densidade lexical e terminológica de ambas as línguas se pautou como um principal motivo pela escolha, em virtude da lacuna, por parte dos tradutores ouvintes intermodais profissionais, de conhecimentos referentes a essa área. Todavia, os dados não explicitam se a escolha por esses textos está vinculada a pouca ou a baixa experiência e frequência em traduzi-los, exceto aos textos acadêmicos mencionados, uma vez que os tradutores que o citaram informaram atuar em cursos superiores afins a esse âmbito.

A dificuldade relatada por eles acarreta em constante e intensa mobilização por consulta de dicionários, glossários, materiais paralelos, outras obras já traduzidas e contato com tradutores e especialistas da área para conhecer os termos e a sua significa- 
ção. Novamente, todas essas ações remetem-se à subcompetência instrumental do tradutor. Na Libras, em consonância à ciência da terminologia, a criação e a validação de léxicos especializados têm sido requisitados e problematizados como um mecanismo capaz de auxiliar os tradutores e os demais interlocutores na apropriação e na expressão de variados conceitos, como aprecia Vale (313). Caso não exista esses termos na língua de sinais ou o tradutor os desconheça, a maneira para representar essas informações em Libras poderia ser, somente, por meio da datilologia ou, por ela, acrescida de descritores visuais e/ou ações construídas. Contudo, cabe aos profissionais avaliar quais as estratégias e os formatos seriam mais adequados e produtivos.

Por efeito da dificuldade declarada, a tradutora ouvinte TF3 exterioriza também que a transposição para a língua gestual-visual

\begin{abstract}
"[...] é uma situação difícil quando a gente não está segura do assunto, não conhece a área e não encontra sinais, mas precisa gravar a tradução. É uma exposição muito grande porque as pessoas vão assistir depois".
\end{abstract}

Esse ponto resgata, mais uma vez, os componentes psicofisiológicos, como a insegurança, podendo inibir ou reduzir a qualidade da atuação. Ainda, TM6 acrescenta que "traduzir um texto que não sabemos os sinais específicos causa preocupação porque os surdos podem não entender". Certamente, a intenção dos profissionais é executar o seu trabalho da melhor maneira possível, permitindo que a mensagem traduzida alcance o público na língua de chegada. Entretanto, por mais que os signos verbais específicos sejam encontrados e empregados, os receptores podem não os (re)conhecer. Por isso, as traduções, assim como os textos originais, também são fontes de informação discursiva e, até mesmo, vocabular.

É interessante verificar que temos caminhado a uma vertente formativa e profissional em que as pessoas estão compreendo as especificidades textuais, linguísticas, referenciais e emocionais que 
cada (con)texto impõe ao tradutor. Assim, a nível de formação e de capacitação, é válido expor os aprendizes e os profissionais às práticas de tradução em diversos tipos e gêneros textuais (Campos e Leipnitz 1743).

Finalmente, diante desta pequena entrevista realizada, percebemos alguns pontos nevrálgicos em relação à tradução como o par linguístico, a direção de atuação, os instrumentos para preparação, a fonte textual e os aspectos emocionais e afins imbricados a todo o processo. Nessa perspectiva, compactuamos com Rodrigues (311) ao pensar em uma competência tradutória intermodal, em razão da diferença de modalidade linguística suscetibilizar o processo, apesar de alguns componentes dessa competência serem comuns àqueles intramodais vocais-auditivos.

\section{Considerações finais}

Perante as peculiaridades que o processo tradutório impele, há um consentimento entre autores, pesquisadores, professores e profissionais da necessidade em se desenvolver a competência tradutória dos tradutores-em-formação, a fim de diferenciá-los dos demais falantes bilíngues (Hurtado Albir 19). Além disso, difundir o entendimento de que não se trata de uma predisposição inata para tal, mas, na verdade, viabiliza-se por alinhar um conjunto de conhecimentos, habilidades, atitudes e valores que, relacionados, constituirão essa competência (Galán-Mañas 2), não se limitando meramente àquelas voltadas às concepções linguísticas e/ou comunicativas.

Por outro lado, ao se pensar em atuações intermodais, é preciso tecer reflexões de ordem linguística específica, compreendendo a dinâmica modal inerente às línguas de sinais. Nesse sentido, Rodrigues (291) nos leva a (re)pensar os modelos existentes, apontando, para tradutores (ouvintes) intermodais, subcompetências que promovam a aquisição e o aprimoramento de questões corporais e motoras, contribuindo para o processo tradutório de sinalização. Além dessa, no sentido da tradução de uma língua gestual-visual para outra vo- 
cal-auditiva, o referido autor salienta a apreensão e o aprimoramento de capacidades visuais-cognitivas para que se capte a totalidade das informações produzidas no espaço multidimensional. Destarte, habilidades de observação (e.g., leitura) e de registro (e.g., escrita), enquanto compreensão e produção de mensagens retidas e transmitidas em um suporte, parecem ser fundamentais aos tradutores.

Para implicações futuras, outra vertente que carece de ser examinada são as competências a serem aprofundadas e aperfeiçoadas aos tradutores surdos, visto que, para eles, na maioria dos casos, a Libras é a primeira língua e o português, a segunda. Nesse formato, haveria um agrupamento de conhecimentos e de habilidades relacionadas à língua vocal-auditiva a serem trabalhados, levando em conta, também, as especificidades modais da língua gestual-visual, como retratam Rodrigues e Ferreira (118-119). Pensar a esse respeito é importante, visto que, nos atuais cursos de formação inicial de tradutores intramodais vocais-auditivos e intermodais é praticamente inexistente as discussões relacionadas às especificidades da primeira língua como observam Faria e Galán-Mañas (282) e Rodrigues (204). Ainda, questões de direcionalidade do processo também merecem estar em pauta, pois, com a profissionalização dos tradutores e/ou intérpretes surdos, em virtude da ampliação dos campos de trabalho, a Libras oral pode ser a língua de chegada, partindo, por exemplo, do português escrito, de outras línguas de sinais ou de sinais internacionais, e vice-versa. Stone (99) defende a atuação de tradutores e/ou intérpretes surdos, por admitir que esses sujeitos, nativos na língua de sinais, teriam maiores e melhores subsídios, sobretudo linguísticos-culturais, ao oferecer um produto final como texto de chegada sinalizado ao público surdo.

\section{Agradecimentos}

Aos tradutores, que participaram desta pesquisa, e aos pareceristas, pelos apontamentos ao longo do artigo. 


\section{Referências}

ALVES, Fábio. Ritmo cognitivo, meta-função e experiência: parâmetros de análise processual no desempenho de tradutores novatos e experientes. In: PAGANO, Adriana; MAGALHÃES, Célia; ALVES. Fábio. (Org.). Competência em tradução: cognição e discurso. Belo Horizonte: UFMG, 2005: 109-169.

ANDRADE, Betty Lopes L'Astorina de. Literatura surda em Língua Brasileira de Sinais: tradução com foco no antropomorfismo. In: RIGO, Natália Schleder. (Org.). Textos e Contextos Artísticos e Literários: tradução e interpretação em Libras, 3 (2020): 16-31.

ARAUJO, Sofia Paiva de; FONSECA, Norma Barbosa de Lima. Conhecimento de domínio e subcompetências bilíngue, instrumental e conhecimento sobre tradução na avaliação de qualidade de traduções de manuais de instrução: um estudo sob a perspectiva do avaliador. Letras \& Letras, 352 (2019): 79-103, Uberlândia: UFU. Disponível em: http://www.seer.ufu.br/index.php/letraseletras/article/ view/50856/28219. Acesso em 10/04/2020.

AVELAR, Thaís Fleury. Análise da tradução intermodal de texto acadêmico do português escrito para a Libras em vídeo. 2020, $218 \mathrm{f}$. Tese (Doutorado em Estudos da Tradução) - Centro de Comunicação e Expressão. Universidade Federal de Santa Catarina, Florianópolis, 2020.

BARROS, Mariângela Estelita. Elis - Sistema brasileiro de escrita das línguas de sinais. São Paulo: Editora Penso, 2015, pp. 144.

BENASSI, Cláudio Alves. O despertar para o outro: entre as escritas de sinais. Rio de Janeiro: Autografia, 2017.

CAMPOS, Tania Liparini; LEIPNITZ, Luciane. Competência Tradutória: o desenvolvimento da subcompetência sobre conhecimentos em tradução. Domínios de Lingu@gem, 115 (2017): 1727-1745, Uberlândia: UFU. Disponível em: http:// www.seer.ufu.br/index.php/dominiosdelinguagem/article/view/37449/21497. Acesso em 23/06/2019. 
CARNEIRO, Teresa Dias; VITAL, Dafny Saldanha Hespanhol; SOUZA, Rodrigo Pereira Leal de. O processo de produção de textos traduzidos para Libras em vídeo no Departamento de Letras-Libras (UFRJ) comparado ao processo de produção de traduções editoriais entre línguas orais. Belas Infiéis, 95 (2020): 135-166, Brasília: UnB. Disponível em: https://periodicos.unb.br/index.php/ belasinfieis/article/view/31990/27818. Acesso em 09/10/2021.

DIAS, Vitor de Souza; NASCIMENTO, Vinícius. Tradução comentada da Escala de Ansiedade a Matemática (eam) para a Língua Brasileira de Sinais (Libras): questões teóricas e implicações formativas. Revista Espaço, 51 (2019): 59-81, Rio de Janeiro: INES. Disponível em: http://www.ines.gov.br/seer/index.php/ revista-espaco/article/view/600/pdf. Acesso em 07/04/2020.

DUARTE, Rosália. Entrevistas em pesquisas qualitativas. Revista Educar, 24 (2004): 213-225.

FARIA, Juliana Guimarães; GALÁN-MAÑAS, Anabel. Um estudo sobre a formação de tradutores e intérpretes de Línguas de Sinais. Trabalhos em Linguística Aplicada, 571 (2018): 265-286, Campinas: Unicamp. Disponível em: https:// periodicos.sbu.unicamp.br/ojs/index.php/tla/article/view/8651551/17747. Acesso em: 20/05/2019.

FERREIRA, Alice Maria Araújo; SILVA-NETO, Virgílio Soares da. Tradução de teatro para línguas de sinais: ensaio sobre corpo e (in)visibilidade. Cadernos de Tradução, 401 (2020): 72-90, Florianópolis: UFSC. Disponível em: https://periodicos.ufsc.br/index.php/traducao/article/view/2175-7968.2020v40n 1p72/42359. Acesso em: 18/04/2020.

FERREIRA, Aline Alves. Direcionalidade em tradução: o papel da subcompetência bilíngue em tarefas de tradução L1 e L2. 2013, 164 f. Tese (Doutorado em Linguística Aplicada) - Faculdade de Letras. Universidade Federal de Minas Gerais, Belo Horizonte, 2013.

FONSECA, Norma Barbosa de Lima; GONÇALVES, José Luiz Vila Real; ZAMPIER, Pedro. Investigando o esforço cognitivo, o conhecimento sobre tradução e a satisfação na tradução Libras-Português. Cadernos de Tradução, 39 3 (2019): 20-49, Florianópolis: UFSC. Disponível em: https://periodicos.ufsc. br/index.php/traducao/article/view/2175-7968.2019v39n3p20/40840. Acesso em 05/03/2020. 
GALÁN-MAÑAS, Anabel. Learning portfolio in translator training: the tool of choice for competence development and assessment. The Interpreter and Translator Trainer, 2016, pp. 1-22. Disponível em: https://doi.org/10.1080/175 0399X.2015.1103108. Acesso em 18/05/2019.

GIL, Antônio Carlos. Métodos e técnicas de pesquisa social. 6. ed. São Paulo: Atlas, 2008, pp. 201.

GONÇALVES, José Luiz Vila Real. Repensando o desenvolvimento da competência tradutória e suas implicações para a formação do tradutor. Revista Graphos, 171 (2015): 114-130, João Pessoa: UFPB. Disponível em: https://periodicos.ufpb.br/ index.php/graphos/article/view/25053. Acesso em 28/02/2019.

HURTADO ALBIR, Amparo. A aquisição da competência tradutória: aspectos teóricos e didáticos. In: PAGANO, Adriana; MAGALHÃES, Célia; ALVES. Fábio. (Org.). Competência em tradução: cognição e discurso. Belo Horizonte: UFMG, 2005, pp.19-57.

HURTADO ALBIR, Amparo. Traducción y traductología. Madrid: Gredos, 5. ed, 2011, pp. 696.

KIRALY, Donald. C. Translation into a non-mother tongue: From collaboration to competence. In: GROSMAN, Meta; KRADIC, Mira; KOVACIC, Irena; SNELL-HORNBY, Mary. (Org.). Translation into non-mother tongues in professional practice and training, Tubingen: Stauffenburg Verlag, 2000, pp. $117-124$.

KLAMT, Marilyn Mafra. Tradução comentada do poema em Língua Brasileira de Sinais "Voo sobre rio". Belas Infiéis, 32 (2014): 107-123, Brasília: UnB. Disponível em: https://periodicos.unb.br/index.php/belasinfieis/article/ view/11285/9930. Acesso em: 16/10/2018.

LESSA-DE-OLIVEIRA, Adriana Stella Cardoso. Libras escrita: o desafio de representar uma língua tridimensional por um sistema de escrita linear. ReVel, 10 9 (2012): 150-184. Disponível em: http://www.revel.inf.br/files/4566006ab74ec ff8dc54d92e9649eb86.pdf. Acesso em 01/05/2019. 
LOGUERCIO, Sandra Dias; SILVA, Márcia Moura. Estudo exploratório: que temas são traduzidos e/ou pesquisados em cursos de tradução no Brasil?. Cultura e Tradução, 61 (2020): 69-85, João Pessoa: UFPB. Disponível em: https://periodicos.ufpb.br/index.php/ct/article/view/49179/30089. Acesso em 10/05/2020.

MANZINI, Eduardo José. Considerações sobre a elaboração de roteiro para entrevista semi-estruturada. In: MARQUEZINE, Maria Cristina; ALMEIDA, Maria Amélia; OMOTE; Sadao. (Org). Colóquios sobre pesquisa em Educação Especial. Londrina: Eduel, 2003, pp. 11-25.

McCLEARY, Leland; VIOTTI, Evani; LEITE, Tarcísio de Arantes. Descrição das línguas sinalizadas: a questão da transcrição dos dados. Revista Alfa, 541 (2010): 265-289, Unesp. Disponível em: https://periodicos.fclar.unesp.br/alfa/ article/view/2880/2654. Acesso em: 05/05/2019.

NASCIMENTO, Marcus Vinícius Batista. Interpretação da língua brasileira de sinais a partir do gênero jornalístico televisivo: elementos verbo-visuais na produção de sentidos. 2011, 148 f. Dissertação (Mestrado em Linguística Aplicada e Estudos da Linguagem) - Programa de Estudos Pós-Graduados em Linguística Aplicada e Estudos da Linguagem, Pontifícia Universidade Católica de São Paulo, São Paulo, 2011.

NASCIMENTO, Vinícius; NOGUEIRA, Tiago Coimbra. Tradução Audiovisual e o direito à cultura: o caso da comunidade surda. PERcursos Linguísticos, 9 21 (2019): 105-132, Vitória: UFES. Disponível em: http://periodicos.ufes.br/ percursos/article/view/23740. Acesso em: 10/02/2020.

NORD, Christiane. Análise textual em tradução: bases teóricas, métodos e aplicação didática. Coordenação da tradução e adaptação de Meta Elisabeth Zipser. São Paulo: Rafael Copetti Editor, 2016, pp. 441.

PAVLOVIĆ, Nataša; JENSEN, Kristian Tangsgaard Hvelplund. "Eye tracking translation directionality." In: PYM, Anthony; PEREKRESTENKO, Alexander. (Org.) Translation Research Projects. Intercultural Studies Group, 2 ed. 2009, pp. 93-109.

QUADROS, Ronice Muller de; SOUZA, Saulo Xavier. Aspectos da tradução/ encenação na Língua de Sinais Brasileira para um ambiente virtual de ensino:

Cad. Trad., Florianópolis, v. 41, $\mathrm{n}^{0}$ esp. 2, p. 40-67, ago/dez, 2021. 
práticas tradutórias do curso de Letras-Libras In: QUADROS, Ronice Muller de. (Org). Estudos Surdos III. Petrópolis, Rio de Janeiro: Arara-Azul, 2008, pp. 168-207.

QUADROS, Ronice Muller de; PIZZIO, Aline Lemos. Língua brasileira de sinais IV. Curso de graduação de Letras Libras. Universidade Federal de Santa Catarina, 2009.

RIGO, Natália Schleder. Tradução de Libras para Português de texto acadêmicos: considerações sobre a prática. Cadernos de Tradução, 352 (2015): 428-478, Florianópolis: UFSC. Disponível em: https://periodicos.ufsc.br/index.php/ traducao/article/view/2175-7968.2015v35nesp2p458/30721. Acesso em: 19/03/2016.

RIGO, Natália Schleder. Tradução de textos acadêmicos de Português para Língua Brasileira de Sinais: o emprego de elementos do design editorial como soluções tradutórias. Translatio, 15 (2018): 173-196, Porto Alegre: UFRGS. Disponível em: https://seer.ufrgs.br/translatio/article/view/81442/48550. Acesso em: 24/01/2019.

RODRIGUES, Carlos Henrique. A interpretação para a Língua de Sinais Brasileira: efeitos de modalidade e processos inferenciais. 2013, 255 f. Tese (Doutorado em Linguística Aplicada) - Faculdade de Letras. Universidade Federal de Minas Gerais, Belo Horizonte, 2013.

RODRIGUES, Carlos Henrique. Competência em tradução e línguas de sinais: a modalidade gestual-visual e suas implicações para uma possível competência tradutória intermodal. Trabalhos em Linguística Aplicada, 571 (2018a): 287-318, Campinas: Unicamp. Disponível em: https://www.scielo.br/pdf/tla/v57n1/01031813-tla-57-01-0287.pdf. Acesso em: 03/02/2019.

RODRIGUES, Carlos Henrique. Formação de intérpretes e tradutores de língua de sinais nas universidades federais brasileiras: constatações, desafios e propostas para o desenho curricular. Translatio, 15 (2018b): 197-222, Porto Alegre: UFRGS. Disponível em: https://seer.ufrgs.br/translatio/article/view/79144/48558. Acesso em 24/01/2019.

RODRIGUES, Carlos Henrique. Translation and sign language: highlighting the visual-gestural modality. Cadernos de Tradução. Florianópolis, 382 (2018c): 
294-319, Florianópolis: UFSC. Disponível em: https://www.scielo.br/pdf/ct/ v38n2/2175-7968-ct-38-2-0294.pdf. Acesso em: 25/01/2019.

RODRIGUES, Carlos Henrique; BEER, Hanna. Os Estudos da Tradução e da Interpretação de Línguas de Sinais: novo campo disciplinar emergente? Cadernos de Tradução, 352 (2015): 17-45, Florianópolis: UFSC. Disponível em: https://periodicos.ufsc.br/index.php/traducao/article/view/2175-7968.2015v 35nesp2p17. Acesso em: 19/03/2016.

RODRIGUES, Carlos Henrique; FERREIRA, João Gabriel Duarte. Tradutores, intérpretes e guias-intérpretes surdos: prática profissional e competência. Revista Espaço, 51 (2019): 109-125, Rio de Janeiro: INES. Disponível em: http://www. ines.gov.br/seer/index.php/revista-espaco/article/view/604/662. Acesso em: 07/04/2020.

SANTOS, Emerson Cristian Pereira dos. No princípio era a palavra, mas a palavra foi traduzida para os sinais. Cadernos de Tradução, 383 (2018): 93124, Florianópolis: UFSC. Disponível em: https://periodicos.ufsc.br/index.php/ traducao/article/view/2175-7968.2018v38n3p93/37388. Acesso em: 13/07/2019.

SANTOS, Silvana Aguiar dos. Tradução/Interpretação de Língua de Sinais no Brasil: uma análise das teses e dissertações de 1990 a 2010. 2013, 313 f. Tese (Doutorado em Estudos da Tradução) - Centro de Comunicação e Expressão. Universidade Federal de Santa Catarina, Florianópolis, 2013.

SANTOS, Silvana Aguiar dos. Estudos da Tradução e Interpretação de Línguas de Sinais nos programas de pós-graduação em Estudos da Tradução. Revista da Anpoll, 144 (2018): 375-394. Disponível em: https://revistadaanpoll.emnuvens. com.br/revista/article/view/1148/959. Acesso em: 14/03/2019.

SANTOS, Sheila Maria dos; ROMANELLI, Sergio. Sobre a (in)visibilidade do escritor-tradutor: em busca de Mario Quintana e Fernando Py. Letras \& Letras, 321 (2016): 267-282, Uberlândia: UFU. Disponível em: http://www.seer.ufu. br/index.php/letraseletras/article/view/32989/18700. Acesso em: 10/04/2020.

SEGALA, Rimar Romano; QUADROS, Ronice Muller de. Tradução intermodal, intersemiótica e interlinguística de textos escritos em Português para a Libras oral. Cadernos de Tradução, 352 (2015): 354- 386, Florianópolis: UFSC. Disponível 
em: https://periodicos.ufsc.br/index.php/traducao/article/view/21757968.2015v3 5nesp2p354/30718. Acesso em: 19/03/2016.

SOUZA, Saulo Xavier. Performances de tradução para a Língua Brasileira de Sinais observadas no curso de Letras-Libras. 2010, 174 f. Dissertação (Mestrado em Estudos da Tradução) - Centro de Comunicação e Expressão. Universidade Federal de Santa Catarina, Florianópolis, 2010.

SPOONER, Ruth Anna; SUTTON-SPENCE, Rachel; LERNER, Miriam Nathan; LERNER, Kenny. Invisible no More: Recasting the Role of the ASL-English Literary Translator. Translation and Interpreting Studies, 131 (2018): 110-129.

STONE, Christopher. Entrevista - interview. In: RODRIGUES, Carlos. Henrique; SUTTON-SPENCE, Rachel Louise. (Org.). Coleção palavras de Tradutor. Tradução inglês-português de Vitória Tassara e Hanna Beer; Tradução português-libras João Gabriel Ferreira e Victória Pedroni, 1. ed. Curitiba: Medusa, 2020, pp. 152. Disponível em: https://drive.google.com/file/d/1S1neDsfMxeIBuN9olYDFCi_WSpeBX-D/view. Acesso em 06/05/2020.

STUMPF, Marianne Rossi. Aprendizagem da escrita de língua de sinais pelo sistema de SignWriting: língua de sinais no papel e no computador. 2005, 330 f. Tese (Doutorado em Informática na Educação). Universidade Federal do Rio Grande do Sul, Porto Alegre, 2005.

SUTTON-SPENCE, Rachel. Considerations for translating "grande sertão veredas" into Libras. Revista da Anpoll, 1 (2018): 192-206. Disponível em: https://pdfs.semanticscholar.org/e8a5/457f8a200778898bca4225ea9402b8 6b0496.pdf. Acesso em: 14/03/2019.

VALE, Luciana Marques. A importância da terminologia para o tradutor/ intérprete de Língua de Sinais Brasileira. Translatio, 15 (2018): 305-320, Porto Alegre: UFRGS. Disponível em: https://seer.ufrgs.br/translatio/article/ view/81599/48548. Acesso em 08/09/2020.

Eduardo Andrade Gomes. E-mail: edu.gomes06@gmail.com. https://orcid. org/0000-0003-3571-3644.

Thaís Fleury Avelar. E-mail: thaisfleury@ufg.br. https://orcid.org/0000-00024237-9093.

Cad. Trad., Florianópolis, v. 41, $\mathrm{n}^{0}$ esp. 2, p. 40-67, ago/dez, 2021. 